\title{
Analysis of Th17 cells in ovarian cancer in terms of their clinical significance
}

J.Kotarski, M. Bilska, A. Pawłowska, D. Suszczyk, R. Tarkowski, B. Barczyński, I. Wertel

\section{$1^{\text {st }}$ Department of Oncological Gynecology and Gynecology Medical University of Lublin, Poland}

\section{Aim}

The aim of the study was evaluation of Th17 cells in patients with different clinical manifestation of ovarian cancer (OC) in three environment: peripheral blood (PB), peritoneal fluid (PF) and tissue (TT), and establish their role in OC pathogenesis.

\section{Methods}

The study included 59 patients with OC, 35 women with benign ovarian tumors and 10 healthy donors. The percentage of Th17 cells was analyzed by flow cytometry. Th17 cells were analyzed as percentage of CD4+ with intracellular expression of IL-17A.

\section{Results}

The highest percentage of Th17 cells was detected among tumor infiltrating CD4+ lymphocytes and it was significantly higher $(p=0.001)$ than in PB. The percentage of Th17 cells in both, PB and PF of patients with OC was lower $(p<0.0001)$ than in benign tumors group. There was no significant differences in the percentage of Th17 cells in PB, PF and TT in relation to FIGO stages, histopathological grading, Kurman and Shih's type.

There was no relationship between the percentage of Th17 cells in PB, PF, TT and patients survival.

Table 1, Figure 1

Assessment of the percentage of Th17 lymphocytes in peripheral blood, peritoneal fluid and among ovarian cancer infiltrating cells

\begin{tabular}{|c|c|c|c|}
\hline & \multicolumn{3}{|c|}{ Percentage of CD4+IL-17+cells } \\
\cline { 2 - 4 } & median & minimum & maximum \\
\hline $\begin{array}{c}\text { Peripheral blood } \\
(n=59)\end{array}$ & 0.67 & 0.05 & 3.28 \\
\hline $\begin{array}{c}\text { Peritoneal fluid } \\
(n=35)\end{array}$ & 0.50 & 0.05 & 2.52 \\
\hline $\begin{array}{c}\text { Tumor } \\
(n=17)\end{array}$ & 1.78 & 0.20 & 19.28 \\
\hline
\end{tabular}

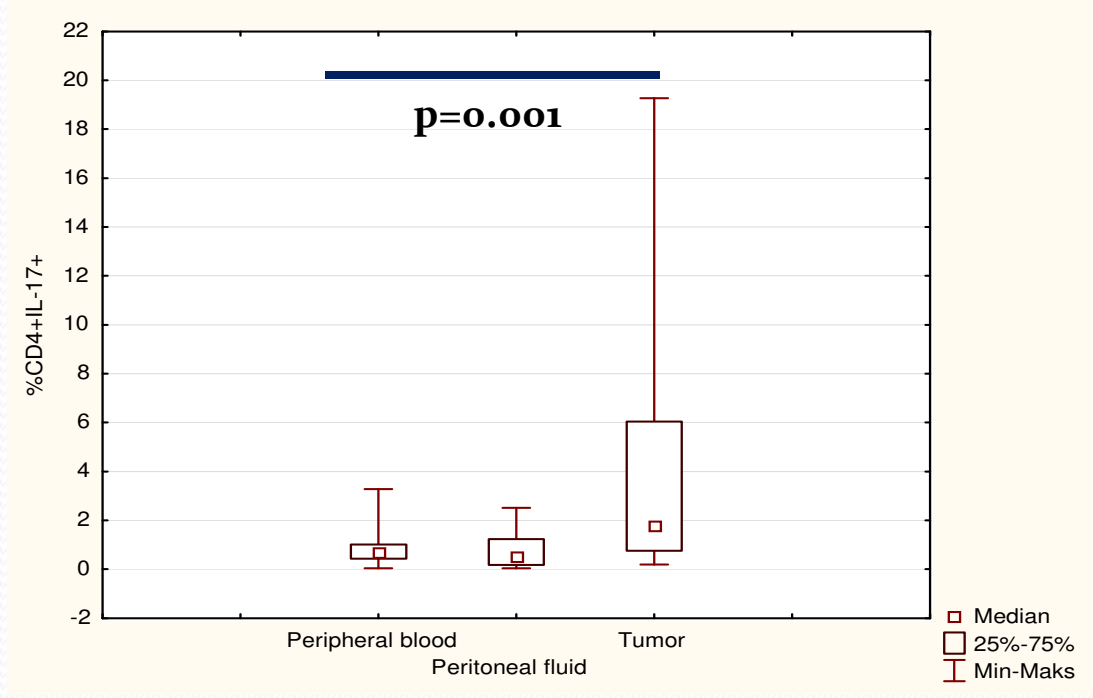

\section{Figure 2}

Percentage of Th17 cells in PB and PF of patients with OC and in the group with benign ovarian tumor
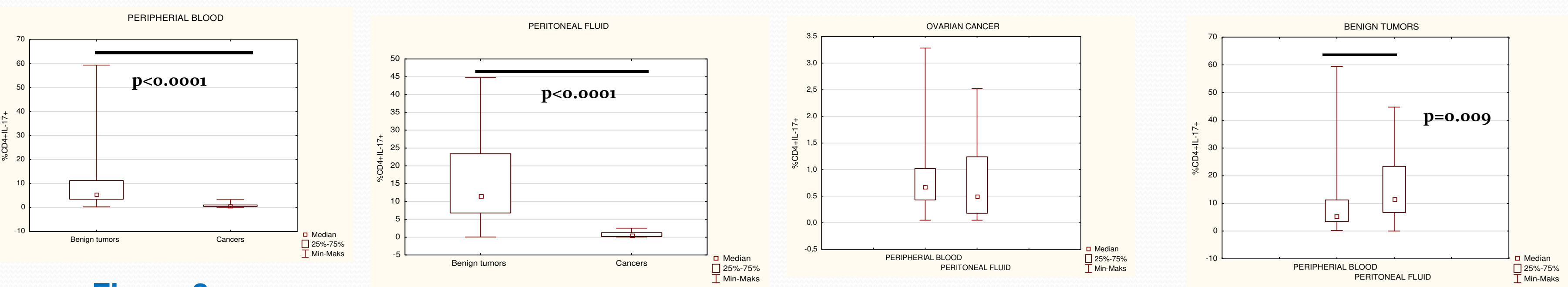

Figure 3

Relationship between the percentage of Th17 lymphocytes and ovarian cancer patients survival
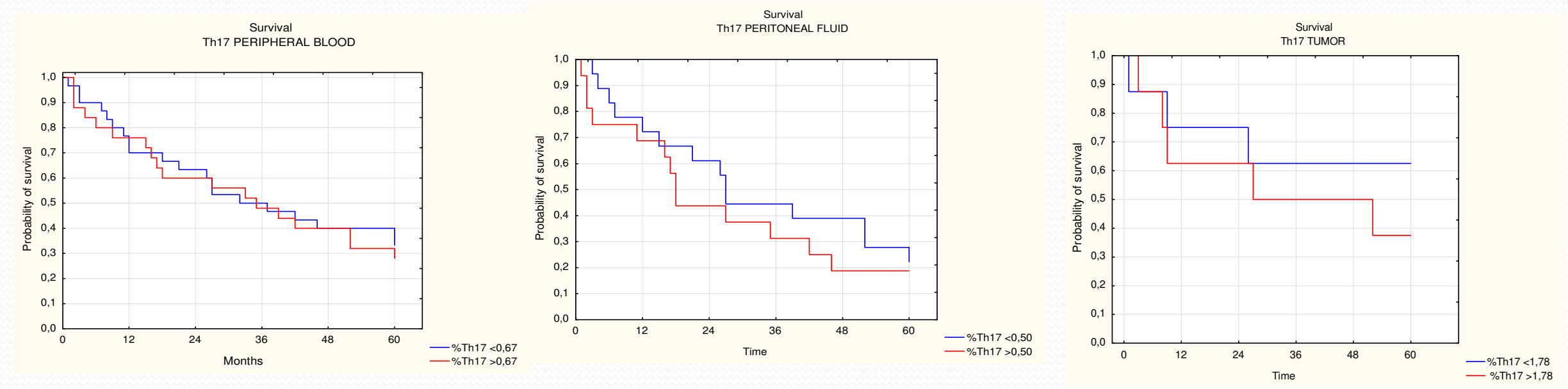

\section{Conclusions}

There are differences in the percentage and distribution of Th17 cells in the PB, PF and tumor tissue of OC patients.

Lower percentage of Th17 cells in the PB and PF of OC patients in comparison to benign tumors may promote evade host immune response by cancer cells.

There were no significant differences in the percentage of Th17 cells in OC patients depending on FIGO stage, histological grade, Kurman and Shih's type and five-years survival rate of patients. 